\title{
Estudo geoambiental da região circunjacente ao emissário submarino de esgoto do Araçá, São Sebastião (SP)
}

\author{
Silas Gubitoso', Wânia Duleba², Andreia C. Teodoro' ${ }^{1}$,Silvio Miranda Prada ${ }^{3}$, Marcelo M. da Rocha', \\ Claudia Conde Lamparelli, José Eduardo Bevilacqua ${ }^{3,4}$ \& Débora Ogler Moura ${ }^{4}$
}

\begin{abstract}
Resumo O objetivo deste estudo foi realizar caracterização hidroquímica, microbiológica e sedimentológica da região circunjacente aos difusores do emissário submarino de esgoto do Araçá, Canal de São Sebastião, SP. Para atingir esse objetivo foram coletadas 10 amostras de água (superfície, meio e fundo) e 9 amostras de sedimento superficial, para avaliar o comportamento da pluma de esgoto e seus possíveis efeitos em ambiente marinho. Os resultados hidroquímicos e microbiológicos indicaram que a coluna d'água não estava contaminada, no momento da amostragem, pois todos os valores obtidos estavam dentro dos limites exigidos pela legislação CONAMA. Contudo, ressalta-se que essa legislação não é específica para controle dos lançamentos de emissários submarinos. Em contrapartida, os resultados granulométricos e geoquímicos de C, N, S e especiação de P demonstraram que o sedimento arenoso fino é rico em nutrientes e em matéria orgânica em decomposição. Os valores elevados de nutrientes indicaram que os sedimentos da região circunjacente ao emissário estão em processo de enriquecimento. Ao se comparar os parâmetros hidroquímicos e biológicos com os sedimentológicos, foi evidenciado que os sedimentos representam o depósito final do material particulado e dos poluentes a eles associados, registrando, portanto, em caráter mais permanente, a contaminação à qual o ecossistema aquático foi submetido.
\end{abstract}

Palavras-chave: emissário submarino, esgoto doméstico, análises hidroquímicas e geoquímicas.

\begin{abstract}
Geo-environmental study near the submarine outfall sewage of Araçá bay in the São Sebastião channel, SP, Brazil. The objective of this study was the hydrochemical, microbiological and sedimentological characterization near the submarine outfall sewage diffusers area of Araçá Bay in the São Sebastião Channel, São Paulo, Brazil. Ten water samples were collected (surface, middle and bottom) and nine of surface sediment in July, 2005, to evaluate the behavior of the sewage plume and its possible effect on the marine environment. The hydrochemical and microbiological results indicate that the water column was not contaminated by the sewage at the moment of sampling, because the values were within of the limits defined by legislation of Brazilian National Environmental Council. However, it must be pointed out that this legislation does not specify controls for submarine effluent outfall. The grain size and geochemical results for C, N, S and inorganic and organic of $\mathrm{P}$ demonstrated that, on average, bottom sediments (fine sand) were rich in nutrients and decomposing organic matter (O.M). The high values of nutrients indicated that the sediments near outfall are in enrichment process. Comparing hydrochemical and biological parameters with geochemical of the sediments, revealed that the sediments represent the final deposit of pollutants associated with particulate material. So, such sediments are more permanently contaminated than the overlying aquatic environmental.
\end{abstract}

Keywords: submarine outfall, sewage, hydrochemical and sedimentological analyses.

INTRODUÇÃO O lançamento de esgotos domésticos é um dos tipos mais comuns de poluição dos oceanos, seja por meio de poluição difusa nos cursos d'água, seja por meio de fontes pontuais, como por exemplo, os emissários submarinos (Lamparelli 2006).

Os emissários submarinos apesar de serem alternativas viáveis, no tocante a diminuição de poluição próxima à linha de costa, necessitam de constante monitoramento, pois os possíveis impactos causados ao meio ambiente vão desde a contaminação microbiológica, aumento de matéria orgânica, turbidez a processos de eutrofização em decorrência de enriquecimento orgânico.
Para minimizar impactos ambientais, muitos países que utilizam o sistema de disposição oceânica, fazem uso de tratamentos que vão do primário ao terciário. Entretanto, no Brasil, os esgotos dispostos somente são pré-condicionados, ou seja, é feita a retirada de sólidos de maior dimensão, desarenação e cloração. Desta forma, toda a porção orgânica e inorgânica é depositada nos sedimentos, podendo retornar a coluna d'água em casos de ressuspensão, bem como alterar a microfauna local.

Diante do exposto, os objetivos do presente estudo foram analisar e caracterizar possíveis alterações ambientais ocorridas em região próxima aos difusores

\footnotetext{
1 - Programa de Geoquímica e Geotectônica, Instituto de Geociências, USP, São Paulo (SP), Brasil. E-mail: silas.gubitoso@usp.br

2 - Instituto de Geociências, USP, São Paulo (SP), Brasil.

3 - Centro Universitário FIEO, UNIFIEO, Osasco (SP), Brasil.

4 - CETESB, Companhia de Tecnologia de Saneamento Ambiental, São Paulo (SP), Brasil.
} 
do emissário submarino do Araçá, São Sebastião - SP, por meio de análises sedimentológicas, microbiológicas e hidrogeoquímicas, bem como avaliar o significado das diferentes informações que os resultados de qualidade da coluna d'agua e dos sedimentos podem fornecer sobre a dispersão dos poluentes lançados pelo emissário em ambiente aquático.

ÁREA DE ESTUDO $O$ canal de São Sebastião (CSS), localizado entre as latitudes $23^{\circ} 40^{\prime} \mathrm{S}$ e $23^{\circ} 53.5^{\prime}$ $\mathrm{S}$ e as longitudes $45^{\circ} 19^{\prime}$ e $45^{\circ} 30^{\prime} \mathrm{W}$, é uma feição de $25 \mathrm{~km}$ de comprimento, que separa o continente da ilha de São Sebastião (Fig. 1). Apresenta larguras variáveis de $2 \mathrm{~km}$ em sua porção central, e $7 \mathrm{~km}$ em suas entradas norte e sul. Seu eixo, onde estão as maiores profundidades (30 a $50 \mathrm{~m}$ ), está deslocado para o lado insular, devido à erosão e/ou condicionamento estrutural das rochas. As profundidades menores $(6 \mathrm{~m})$ ocorrem no lado continental do canal. As entradas sul e norte apresentam profundidades de 25 e $20 \mathrm{~m}$, respectivamente.

A distribuição de sedimentos ao longo do canal está relacionada à sua geometria, topografia de fundo e circulação local. A geometria do canal, mas especificamente sua curvatura, assemelha-se a canal fluvial, apresentando margens deposicional (lado continental) e erosiva (lado insular). A topografia do CSS é irregular, possuindo grandes variações em pequeno espaço, fazendo com que a distribuição dos sedimentos ocorra em manchas, com tamanhos variados (Furtado 1995, Barcellos \& Furtado 1999, 2001).

A circulação do canal se caracteriza por movimentos para norte e sul, com periodicidade de dias, pouco influenciados pelas correntes de maré (Castro-Filho 1999, Fontes 1995, Miranda \& Castro-Filho 1995). A geometria e a topografia do fundo condicionam correntes mais intensas no sentido longitudinal do lado insular, com velocidades de até $1,0 \mathrm{~m} \mathrm{~s}^{-1}$ para o norte e $0,7 \mathrm{~m} \mathrm{~s}^{-1}$ para sul (FUNDESPA 1999). As características termohalinas são determinadas pelo transporte de massas de água da plataforma continental cujos movimentos são predominantemente gerados pelo vento e por forças de gradiente de pressão.

A baía do Araçá, localizada no lado continental do CSS, é uma enseada artificial formada durante a construção do porto de São Sebastião. Apresenta profundidades máximas de $10 \mathrm{~m}$ em sua desembocadura e, em direção ao continente a baía torna-se mais estreita e rasa. Possui pouca declividade e é amplamente descoberta durante a maré baixa. As marés variam entre os níveis médios de +2,06 m (máximo), + 1,15 m (médio)

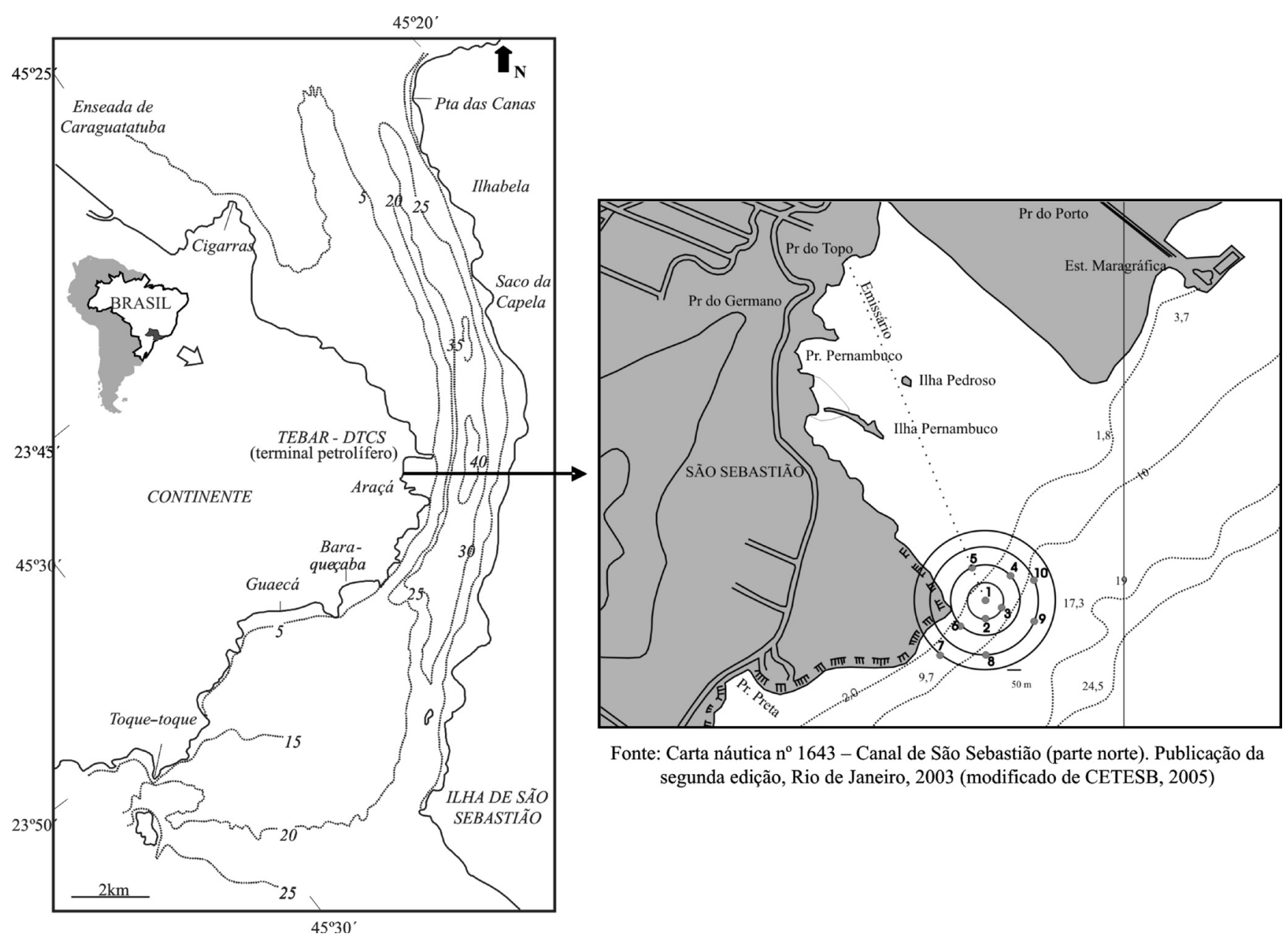

Figura 1 - Mapa da área de estudo e pontos de amostragem. 
e - 0,04 m (mínimo) (Brasil Lima 1998).

Nesta baía localiza-se o emissário submarino para disposição oceânica de esgotos domésticos, que entrou em operação em 1990.

O emissário da Baía do Araçá é composto por duas partes, terrestre e submarina. $\mathrm{O}$ trecho terrestre, com início na praia do Topo, é composto por tubos de ferro fundido, com diâmetro de $400 \mathrm{~mm}$ e extensão de $3.800 \mathrm{~m}$. O trecho submarino é formado por tubulação de polietileno de alta densidade (PEAD) com diâmetro de $400 \mathrm{~mm}$, extensão de $1090 \mathrm{~m}$ e com vazão de 0,14 $\mathrm{m}^{3} \mathrm{~s}^{-1}$ (CETESB 2005). A tubulação submarina é guarnecida de blocos de ancoragem de concreto para garantir seu posicionamento no leito oceânico. Localizado na Ponta do Araçá, a $7 \mathrm{~m}$ de profundidade, o trecho difusor possui $10 \mathrm{~m}$ de comprimento e contém 17 orifícios (CETESB 2005).

MATERIAIS E MÉTODOS A malha de amostragem utilizada continha 10 pontos de coleta distribuídos em círculos concêntricos distanciando-se do ponto de lançamento e abrangendo sua área de influência direta (Fig. 1). A campanha foi realizada em Julho de 2005.

Em cada ponto amostrado foram obtidos dados hidrográficos e, por meio de pegador tipo Petersen, foram coletados sedimentos para análises granulométricas e geoquímicas.

Os dados hidrográficos obtidos foram: profundidade, turbidez, temperatura, salinidade (CTD Seacat), oxigênio dissolvido, $\mathrm{pH}$ (potenciômetro Beckman Zeromatic II). Foram também coletadas amostras de água na superfície, meio e fundo da coluna d'água para análise de nutrientes dissolvidos (nitrogênio amoniacal, nitrogênio Kjeldahl total, fósforo total, ortofosfato), Coliforme Termotolerantes e Enterococos. Os ensaios analíticos da água foram realizados nos laboratórios de análise química da Companhia de Tecnologia de Saneamento Ambiental (CETESB).

As análises granulométricas foram realizadas por meio de peneiramento e pipetagem, conforme descrito em Suguio (1973). Os mapas de isolinhas elaborados para diâmetro médio dos grãos e porcentagem de silte, foram interpolados por meio do programa Geovisual 2.0, utilizando-se o algoritmo de equações multiquádricas.

O teor de carbonato de cálcio foi obtido por diferença de massa após ataque ácido ( $\mathrm{HCl}$ a $10 \%)$ (Gross 1971). A classificação do conteúdo de carbonato biodetrítico foi feita de acordo com o proposto por Larsonneur et al. (1982).

As análises geoquímicas realizadas foram: carbono orgânico $(\mathrm{C}$ org), nitrogênio $(\mathrm{N})$, enxofre $(\mathrm{S})$ e especiação de fósforo (fósforo total - $\mathrm{P}$ total, orgânico - P org e inorgânico - $\mathrm{P}$ inorg). As análises de $\mathrm{C}$ org e $\mathrm{N}$ foram realizadas em aparelho $\mathrm{CHN}-1000$, sendo as de S realizadas por meio do aparelho SC-432, ambos da LECO ${ }^{\circledR}$. Para especiação do $P$ foi utilizado o método de Legg \& Black (1955). O P org e P inorg foram determinados pelo método espectrofotométrico do ácido ascórbico (espectrofotômetro Shimadzu, modelo
UV-1601 PC) com adaptação para sistema de análise de injeção de fluxo (Zagatto et al. 1981).

Com base nos dados de C orgânico, $\mathrm{N}$ e P orgânico foram calculadas as razões $\mathrm{C} / \mathrm{N}$ e $\mathrm{C} / \mathrm{P}$, as quais permitem analisar a origem da matéria orgânica (M.O.). Com o intuito de analisar o potencial de oxi-redução dos sedimentos, foram calculadas razões $\mathrm{C} / \mathrm{S}$.

\section{RESULTADOS E DISCUSSÃO}

Parâmetros Hidrográficos (profundidade, temperatura, salinidade, $\mathrm{OD}, \mathbf{p H}$, turbidez) A profundidade dos pontos de amostragem variou de 3 a $17 \mathrm{~m}$ (Tab. 1).

A temperatura da água apresentou pouca variação térmica, os valores obtidos variaram de 22,1 a 22,7 ${ }^{\circ} \mathrm{C}$ (Tab. 1). A salinidade associada à distribuição da temperatura também apresentou fraca estratificação, os valores variaram entre 34,6 e 35,1 (Tab. 1). Observouse diminuição de valores em águas do meio e de fundo e, ligeiramente, nas superficiais no sentido de sudoeste para noroeste. Tal diminuição, ainda que pouco significativa, pode ser decorrente da pluma originada pelo efluente disposto pelo emissário.

As concentrações de OD variaram de 6,33 a $7,60 \mathrm{mg} \mathrm{L}^{-1}$ (Tab. 1). Em todos os pontos verificou-se progressivo decréscimo de concentração de OD da superfície para o fundo da coluna d'água (Tab. 1). Tal padrão foi mais acentuado nas regiões sul e sudeste, principalmente nos pontos 8 e 9 . Comparativamente, as concentrações de OD obtidas no presente estudo são mais elevadas do que as encontradas por Brasil Lima (1998) em alguns pontos analisados na Baía do Araçá. Contudo, todas estão dentro do limite estabelecido pela Resolução do CONAMA 357/2005 (i.e., $6 \mathrm{mg} \mathrm{L}^{-1}$ ). Diante do exposto, pode-se inferir que o efluente disposto pode estar sendo rapidamente diluído e dispersado pelas correntes e/ou marés. Entretanto, ao se calcular a porcentagem de saturação de OD (i.e., a partir da equação da UNESCO, 1973) das águas superficiais da área de influência direta do emissário, foram constatados valores indicativos próximos a saturação (85 a 90\%), a qual pode ser resultado de alta atividade fotossintética do fitoplâncton. Considerando que as coletas foram realizadas durante o dia, com radiação solar intensa, o fitoplâncton, provavelmente, deve ter liberado mais oxigênio na água, provocando sua saturação. Portanto, os valores de OD obtidos provavelmente refletiram a atividade fotossintética e a movimentação das águas.

Com relação aos valores de $\mathrm{pH}$, estes se apresentaram quase homogêneos em toda a coluna d'água. Os valores obtidos variaram de 8,17 a 8,24 (Tab. 1).

Os valores de turbidez obtidos variaram de 0,71 (água de fundo do ponto 3) a 4,30 NTU (água de superfície do ponto 5). De modo geral os menores valores foram observados nas águas de meio e fundo, ocorrendo o contrário com as águas de superfície (Tab. 1).

Parâmetros Hidroquímicos (N amoniacal, N Kjeldahl, Ortofosfato, P total) Os valores de $\mathrm{N}$ amoniacal não ultrapassaram $0,03 \mathrm{mg} \mathrm{L}^{-1}$ (ponto 2), sendo inclusive observado na maioria dos pontos valores in- 
Tabela 1 - Localização, parâmetros hidrográficos, microbiológicos e hidroquímicos obtidos em região próxima ao emissário submarino da Baía do Araçá. Coleta realizada em Julho de 2005.

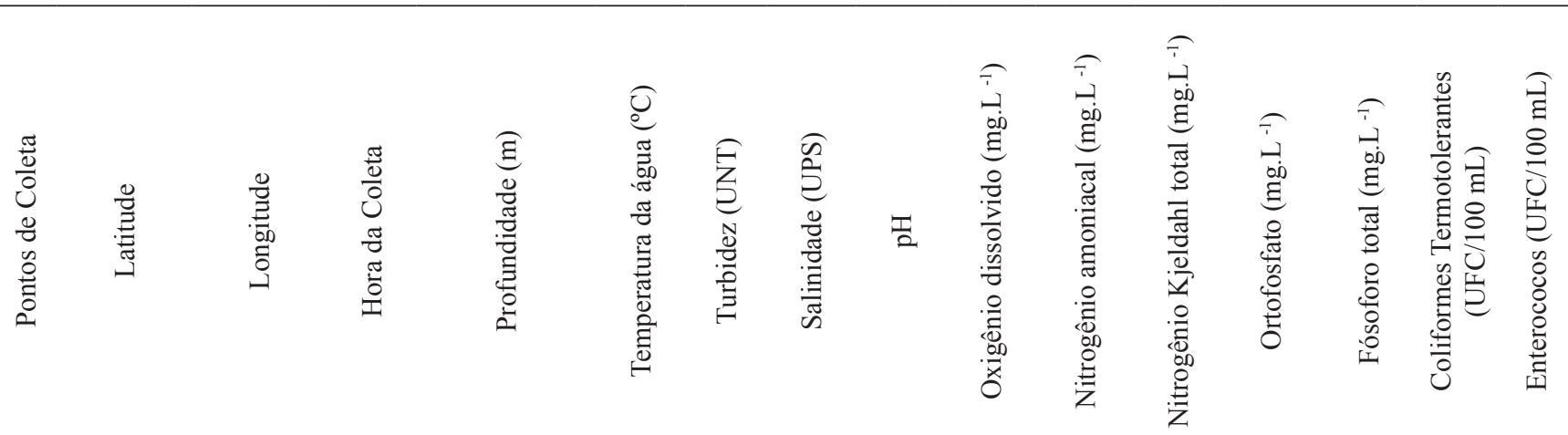

\begin{tabular}{|c|c|c|c|c|c|c|c|c|c|c|c|c|c|c|c|}
\hline & CONAI & 1A $357 / 05$ & & & & & $\geq 30$ & $\begin{array}{c}6,5 \mathrm{a} \\
8,5 \\
\end{array}$ & 6 & 0,4 & & & 0,06 & 1000 & \\
\hline \multirow[t]{3}{*}{1} & 23,81933 & 45,4037 & $09: 45$ & Superfície (0) & 22,3 & 1,5 & 34,8 & 8,17 & 7,19 & $<0,01$ & 0,46 & $<0,01$ & $<0,01$ & 50 & 24 \\
\hline & & & $09: 47$ & Meio (2) & 22,3 & 1,7 & 34,8 & 8,18 & 7,19 & $<0,01$ & $<0,1$ & $<0,01$ & $<0,01$ & 22 & 10 \\
\hline & & & 09:48 & Fundo (3) & 22,3 & 1,8 & 34,7 & 8,18 & 7,16 & $<0,01$ & $<0,1$ & $<0,01$ & $<0,01$ & 34 & 28 \\
\hline \multirow[t]{3}{*}{2} & 23,8198 & 45,4037 & $10: 00$ & Superfície (0) & 23,3 & 2 & 34,6 & 8,19 & 7,17 & 0,3 & 0,21 & 0,2 & 0,2 & 34 & 32 \\
\hline & & & $10: 04$ & Meio (4) & 22,3 & 1,9 & 34,8 & 8,2 & 7,13 & $<0,01$ & $<0,1$ & $<0,01$ & $<0,01$ & 68 & 40 \\
\hline & & & $10: 09$ & Fundo (9) & 22,1 & 1,3 & 34,8 & 8,2 & 6,92 & $<0,01$ & $<0,1$ & $<0,01$ & $<0,01$ & 74 & 56 \\
\hline \multirow[t]{3}{*}{3} & 23,81953 & 45,40325 & $10: 50$ & Superfície (0) & 22,4 & 2 & 34,7 & 8,21 & 7,09 & $<0,01$ & $<0,1$ & $<0,01$ & $<0,01$ & 5 & 3 \\
\hline & & & $10: 56$ & Meio (6) & 22,3 & 1,2 & 34,8 & 8,21 & 7,19 & $<0,01$ & $<0,1$ & $<0,01$ & $<0,01$ & 42 & 30 \\
\hline & & & $11: 02$ & Fundo (12) & 22,5 & 0,71 & 34,9 & 8,22 & 7,16 & $<0,01$ & $<0,1$ & $<0,01$ & $<0,01$ & 72 & 60 \\
\hline \multirow{2}{*}{4} & & & $11: 11$ & Meio (6) & 22,3 & 1,3 & 34,8 & 8,21 & 7,15 & $<0,01$ & $<0,1$ & $<0,01$ & $<0,01$ & 14 & 10 \\
\hline & & & $11: 17$ & Fundo (12) & 22,4 & 1,1 & 34,9 & 8,21 & 7,04 & $<0,01$ & $<0,1$ & $<0,01$ & $<0,01$ & 12 & 6 \\
\hline \multirow[t]{3}{*}{5} & 23,81855 & 45,40405 & $11: 20$ & Superfície (0) & 22,6 & 4,3 & 34,8 & 8,23 & 7,58 & $<0,01$ & $<0,1$ & $<0,01$ & $<0,01$ & 2 & $<1$ \\
\hline & & & $11: 22$ & Meio (2) & 22,6 & 4 & 34,8 & 8,23 & 7,60 & $<0,01$ & $<0,1$ & $<0,01$ & $<0,01$ & 14 & 6 \\
\hline & & & $11: 23$ & Fundo (3) & 22,6 & 4 & 34,8 & 8,18 & 7,60 & $<0,01$ & $<0,1$ & $<0,01$ & $<0,01$ & 10 & 8 \\
\hline \multirow[t]{3}{*}{6} & 23,81997 & 45,40438 & $12: 00$ & Superfície (0) & 22,6 & 3,70 & 34,6 & 8,21 & 7,34 & 0,02 & 0,18 & 0,03 & 0,03 & 4 & 2 \\
\hline & & & $12: 04$ & Meio (4) & 22,6 & 3,8 & 34,8 & 8,22 & 7,15 & $<0,01$ & $<0,1$ & $<0,01$ & $<0,01$ & 32 & 28 \\
\hline & & & $12: 08$ & Fundo (8) & 22,3 & 1,9 & 34,9 & 8,21 & 6,89 & $<0,01$ & $<0,1$ & $<0,01$ & $<0,01$ & 28 & 12 \\
\hline \multirow[t]{2}{*}{7} & 23,82072 & 45,40492 & $14: 25$ & Superfície (0) & 22,7 & 2,2 & 34,9 & 8,21 & 7,34 & $<0,01$ & $<0,1$ & $<0,01$ & $<0,01$ & 6 & 4 \\
\hline & & & $14: 35$ & Fundo (9) & 22,4 & 1,70 & 35,0 & 8,20 & 6,67 & $<0,01$ & $<0,1$ & $<0,01$ & $<0,01$ & 3 & 2 \\
\hline \multirow[t]{3}{*}{8} & 23,82072 & 45,4037 & $14: 45$ & Superfície (0) & 22,5 & 1,5 & 34,9 & 8,23 & 7,25 & $<0,01$ & $<0,1$ & $<0,01$ & $<0,01$ & 2 & $<1$ \\
\hline & & & $14: 50$ & Meio (5) & 22,5 & 1,4 & 34,9 & 8,22 & 7,16 & $<0,01$ & $<0,1$ & $<0,01$ & $<0,01$ & 1 & 1 \\
\hline & & & $14: 56$ & Fundo (11) & 22,1 & 1,5 & 35,1 & 8,18 & 6,33 & $<0,01$ & $<0,1$ & $<0,01$ & $<0,01$ & 4 & 3 \\
\hline \multirow[t]{3}{*}{9} & 23,81988 & 45,40237 & $15: 21$ & Superfície (0) & 22,6 & 1,5 & 34,8 & 8,24 & 7,35 & $<0,01$ & $<0,1$ & $<0,01$ & $<0,01$ & 4 & 2 \\
\hline & & & $15: 29$ & Meio (8) & 22,4 & 0,95 & 35,0 & 8,21 & 7,05 & $<0,01$ & $<0,1$ & $<0,01$ & $<0,01$ & 1 & 1 \\
\hline & & & $15: 38$ & Fundo (17) & 22,2 & 1,2 & 35,1 & 8,20 & 6,53 & $<0,01$ & $<0,1$ & $<0,01$ & $<0,01$ & $\mathrm{x}$ & $\mathrm{x}$ \\
\hline \multirow[t]{3}{*}{10} & 23,81883 & 45,40237 & $15: 55$ & Superfície (0) & 22,5 & 1,9 & 34,8 & 8,22 & 7,28 & $<0,01$ & $<0,1$ & $<0,01$ & $<0,01$ & 3 & 2 \\
\hline & & & $16: 01$ & Meio (6) & 22,4 & 2,3 & 34,9 & 8,22 & 7,21 & $<0,01$ & $<0,1$ & $<0,01$ & $<0,01$ & 6 & 2 \\
\hline & & & $17: 08$ & Fundo (13) & 22,3 & 1,8 & 35,0 & 8,22 & 7,02 & $<0,01$ & $<0,1$ & $<0,01$ & $<0,01$ & 8 & 6 \\
\hline
\end{tabular}

$\mathrm{x}$ - amostra não coletada. 
feriores ao limite de detecção do método analítico, ou seja, 0,01 $\mathrm{mg} \mathrm{L}^{-1}$ (Tabela 1). No tocante aos resultados obtidos para $\mathrm{N}$ Kjeldahl, somente foram observados valores superiores ao limite de detecção nas águas de superfície dos pontos 1 e $2\left(0,46 \mathrm{mg} \mathrm{L}^{-1}\right), 3(0,21 \mathrm{mg}$ $\left.\mathrm{L}^{-1}\right), 4\left(0,12 \mathrm{mg} \mathrm{L}^{-1}\right)$ e $6\left(0,18 \mathrm{mg} \mathrm{L}^{-1}\right)$.

Assim como o observado para $\mathrm{N}$ amoniacal e Kjeldahl, os valores obtidos para Ortofosfato e P total, em sua grande maioria estiveram abaixo do limite de detecção. Somente nas análises da água de superfície dos pontos 2 e 6 foram observados valores superiores a $0,01 \mathrm{mg} \mathrm{L}^{-1}$ para os dois compostos.

Os baixos valores encontrados podem estar demonstrando o potencial de dispersão das correntes dentro do canal em relação ao efluente. Ressalta-se que a velocidade das correntes no CSS é de $1,0 \mathrm{~m} \mathrm{~s}^{-1}$ para o norte e $0,7 \mathrm{~m} \mathrm{~s}^{-1}$ para sul (FUNDESPA 1999).

Os valores obtidos para os nutrientes acima mencionados estão dentro do limite estabelecido pela Resolução CONAMA (357/2005) para águas salinas de classe 1.

Parâmetros Microbiológicos A concentração de coliformes termotolerantes variou de 1 a $74 \mathrm{UFC} / 100 \mathrm{~mL}$ (Tab. 1). Observou-se que as maiores concentrações ocorreram em pontos posicionados próximo à saída do emissário submarino. Tal padrão de distribuição também foi observado para as concentrações de enterococos, cujas con- centrações não ultrapassaram 60 UFC/100mL (Tab.1).

Com relação aos baixos valores obtidos para coliformes termotolerantes e enterococos, algumas hipóteses são possíveis: uma relaciona-se à cloração que ocorre antes do efluente ser disposto, eliminando os microorganismos presentes no esgoto. A outra hipótese é que, estes organismos ao serem eliminados no meio ambiente sofrem decaimento, pois são sensíveis a diversos fatores como salinidade, temperatura e até mesmos outros poluentes existentes nos efluentes (Costa \& Carreira 2005). Mesmo com a cloração e o decaimento bacteriano, seria esperada concentração mais elevadas desses indicadores de poluição fecal. Muitas vezes os baixos índices microbiológicos estão relacionados com a dificuldade em se amostrar a pluma de esgotos propriamente dita. No caso desse emissário especificamente, temos alguns agravantes como a intermitência do lançamento e a pequena vazão (menor ainda nessa época do ano) além do rápido deslocamento da pluma em caso de correntes mais fortes. Desta forma pode estar havendo comprometimento da representatividade dos resultados obtidos.

\section{Dados Sedimentológicos}

Granulometria A composição dos sedimentos variou de silte grosso a areia média (Wentworth 1922) (Tab. 2), com grau de seleção variando de muito pobremente a pobremente selecionado (Folk \& Ward 1957). Com

Tabela 2 - Dados granulométricos obtidos em região próxima ao emissário submarino do Araçá. Coleta realizada em Julho/2005.

\begin{tabular}{|c|c|c|c|c|c|c|c|c|c|c|}
\hline \multirow{3}{*}{ Pontos } & \multirow[b]{2}{*}{ D. Médio } & \multirow[b]{2}{*}{ D. Padrão } & \multirow[b]{2}{*}{ Grânulos } & \multicolumn{4}{|c|}{ Areia } & \multicolumn{3}{|c|}{ Pelíticos } \\
\hline & & & & Mto. Grossa & Grossa & Média & Fina & Mto. Fina & Argila & Silte \\
\hline & $\Phi$ & $\delta$ & $(\%)$ & $(\%)$ & $(\%)$ & $(\%)$ & $(\%)$ & $(\%)$ & $(\%)$ & $(\%)$ \\
\hline 1 & 2,44 & 2,21 & 3,85 & 6,73 & 15,21 & 18,28 & 18,74 & 23,72 & 4,09 & 9,38 \\
\hline 2 & 2,16 & 2,82 & 8,71 & 14,61 & 18,34 & 14,36 & 12,82 & 13,13 & 6,82 & 11,23 \\
\hline 3 & 2,98 & 3,17 & 7,55 & 9,85 & 19,71 & 8,51 & 8,32 & 14,63 & 10,45 & 20,98 \\
\hline 4 & $*$ & * & $*$ & $*$ & $*$ & $*$ & $*$ & * & * & * \\
\hline 5 & 3,99 & 1,61 & 0,00 & 0,37 & 0,48 & 1,48 & 7,21 & 67,56 & 5,80 & 17,10 \\
\hline 6 & 2,19 & 2,26 & 3,14 & 11,66 & 18,16 & 16,81 & 16,82 & 22,09 & 4,21 & 7,11 \\
\hline 7 & 3,53 & 2,75 & 1,60 & 11,39 & 8,00 & 5,96 & 6,18 & 37,75 & 10,43 & 18,68 \\
\hline 8 & 1,81 & 2,19 & 2,56 & 11,91 & 35,48 & 15,28 & 5,06 & 12,28 & 2,19 & 15,25 \\
\hline 9 & 2,27 & 3,00 & 12,59 & 18,45 & 14,42 & 9,86 & 5,68 & 10,37 & 6,67 & 21,95 \\
\hline 10 & 4,12 & 1,96 & 0,36 & 0,36 & 4,52 & 10,46 & 10,10 & 20,96 & 5,47 & 47,77 \\
\hline
\end{tabular}

Obs.: não amostrado 
exceção do ponto 10 , observou-se predominância de termos arenosos, principalmente nos pontos 1 e 6 , cujos percentuais foram 82,7 e $85,5 \%$, respectivamente. Altas concentrações de sedimentos pelíticos foram observadas em pontos posicionados na região leste da saída do emissário submarino. Grânulos foram observados em quase todos os pontos, exceto ponto 5, em porcentagens que variaram de 0,36 a $12,6 \%$.

Ressalta-se que o ponto 4, devido à alta concentração de cascalho, não foi possível coletar sedimento para análises granulométricas e geoquímicas.

Conforme observado no mapa de isolinhas (Fig. 2), elaborado para o diâmetro médio dos grãos e para silte, a região central, local onde está posicionada a parte final do emissário submarino, parece estar sob influência do emissário. O volume do esgoto disposto aparentemente está impedindo a preservação de finos, os quais estão sendo depositados nas regiões norte e nordeste da malha de amostragem, o que permite inferir possível retorno dos mesmos para a linha de costa.

Segundo Furtado (1978), a deposição de sedimentos de granulometria variada, ou seja, grossos a finos deve-se as variações hidrodinâmicas na região central do CSS. Por exemplo, em locais com forte circulação de fundo, há deposição preferencial de termos grossos (Ponta do Guaecá, porção sul do CSS), ocorrendo o contrário em ambientes com circulação de fundo mais fraca, como por exemplo, próximo ao terminal petrolífero, região central. A granulometria encontrada por Furtado (op. cit.) na região do Araçá foi semelhante à verificada nos pontos de amostragem do presente estudo.

Constituintes orgânicos - Carbonato de cálcio, C org, $N$, S e $P$ Os teores de carbonato de cálcio variaram entre 4,02 a 57,34\% (Tab. 3). Segundo a classificação proposta por Larsonneur et al. (1982) nos pontos 1, 5, 6,7 e 10 ocorre sedimentação litoclástica (teores infe-

A) Diâmetro médio (phi)

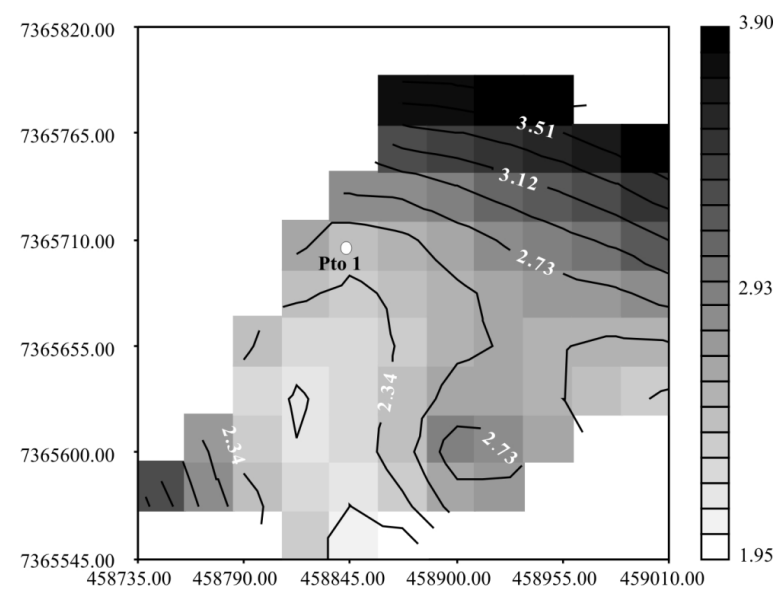

riores a 30\%), ocorrendo nos pontos 2, 3 e 9 sedimentação litobioclástica (entre 30 a 50\%). Somente no ponto 8 observou-se sedimentos biolitoclásticos (entre 50 a $70 \%$ ), devido à elevada concentração de conchas de moluscos. Os resultados obtidos contrapõem aos teores encontrados por Conti (1998) na região (variação de 20 a $25 \%$ ). Tal diferença de teores pode ser explicada pela constante mudança na hidrodinâmica da região.

Os teores de C org variaram de 0,10 a 3,37\% (Tab. 3). As maiores concentrações foram observadas nos pontos $8(3,31 \%)$ e $9(3,37 \%)$. Nestes pontos foram observadas porcentagens 3 a 30 vezes maiores em relação aos demais pontos. As porcentagens de $\mathrm{C}$ org no entorno do emissário do Araçá são superiores as obtidas próximas ao Porto de São Sebastião por Barcellos \& Furtado (1999) e Eichler et al. (1995), ou seja, 1, 66\% e $1,74 \%$, respectivamente. Também foram superiores aos teores obtidos próximo aos emissários da Baía de Guanabara (3,05\%; Rebello et al. 1988) e da Baía de Santos (2\%; Teodoro 2006). As porcentagens encontradas nos pontos 8 e 9, também são mais elevadas do que as observadas nas regiões de Pozzouli - 2,22\% e Castellammare - 2,23\%, ambas na Itália, as quais de acordo com Griggs \& Johnson (1978) encontram-se enriquecidas por C org, em decorrência de disposição de esgotos domésticos e industriais.

As concentrações de $\mathrm{N}$ variaram de 0,01 a $0,10 \%$ (Tab. 3). Os menores valores foram encontrados nos pontos 3,6 e 9, ocorrendo o contrário com o ponto $8(0,10 \%)$. Os valores obtidos no presente estudo foram superiores aos obtidos por Bandy et al. (1964; 0,04\%) próximo ao emissário submarino de esgotos domésticos de Laguna Beach, Califórnia.

As porcentagens de $\mathrm{S}$ variaram de 0,09 (ponto 9) a $0,46 \%$ (ponto 10) (Tab. 3). Em relação aos demais pontos, o 10 apresentou teores superiores 2 a 3 vezes. $\mathrm{O}$ ponto 10 apresentou as maiores concentrações de finos

Figura 2 - Mapas de isolinhas elaborados para diâmetro médio dos grãos (A) e porcentagem de silte (B). 
Tabela 3 - Constituintes orgânicos obtidos em região próxima ao emissário do Araçá. Coleta realizada em Julho/2005.

\begin{tabular}{ccccccccccc}
\hline Pontos & $\begin{array}{c}\text { CaCO3 } \\
(\%)\end{array}$ & $\begin{array}{c}\text { C org } \\
(\%)\end{array}$ & $\begin{array}{c}\mathrm{N} \\
(\%)\end{array}$ & $\begin{array}{c}\mathrm{S} \\
(\%)\end{array}$ & $\begin{array}{c}\text { P total } \\
(\%)\end{array}$ & $\begin{array}{c}\text { P org } \\
(\%)\end{array}$ & $\begin{array}{c}\text { P inorg } \\
(\%)\end{array}$ & Razão C/N & Razão C/P & Razão C/S \\
\hline 1 & 25,9 & 0,12 & 0,05 & 0,11 & 0,08 & 0,002 & 0,081 & 2,4 & 50,4 & 1,1 \\
2 & 42,6 & 0,62 & 0,04 & 0,13 & 0,10 & 0,008 & 0,094 & 15,5 & 75,1 & 5,0 \\
3 & 31,7 & 0,33 & 0,01 & 0,18 & 0,11 & 0,020 & 0,091 & 33,0 & 16,2 & 1,9 \\
4 & $*$ & $*$ & $*$ & $*$ & $*$ & $*$ & $*$ & $*$ & $*$ & $*$ \\
5 & 4,0 & 0,38 & 0,02 & 0,19 & 0,07 & 0,011 & 0,058 & 19,0 & 34,5 & 2,0 \\
6 & 24,5 & 0,14 & 0,01 & 0,09 & 0,11 & 0,013 & 0,093 & 14,0 & 11,1 & 1,6 \\
7 & 10,0 & 0,10 & 0,03 & 0,12 & 0,15 & 0,024 & 0,128 & 3,3 & 4,2 & 0,8 \\
8 & 57,3 & 3,31 & 0,10 & 0,17 & 0,18 & 0,032 & 0,150 & 33,1 & 105,0 & 19,9 \\
9 & 36,2 & 3,37 & 0,01 & 0,20 & 0,19 & 0,033 & 0,159 & 337,0 & 101,9 & 16,7 \\
10 & 21,5 & 1,49 & 0,04 & 0,46 & 0,14 & 0,053 & 0,082 & 37,3 & 28,2 & 3,2 \\
\hline
\end{tabular}

Obs.: * ponto não amostrado

(54\%), indicando que pode estar ocorrendo formação de FeS em provável ambiente redutor.

Os teores de $\mathrm{P}$ org variaram de 0,002 a $0,053 \%$ e de $\mathrm{P}$ inorg de 0,058 a $0,159 \%$ (Tab. 3). As maiores concentrações de $\mathrm{P}$ org ocorreram nos pontos 8,9 e 10 , e as de $\mathrm{P}$ inorg nos pontos 7, 8 e 9 . Comparando-se as concentrações de fósforo orgânico e inorgânico com as concentrações de $\mathrm{C}$ org, observou-se sentido preferencial de deposição para a região sudeste. Em relação ao $\mathrm{P}$ total as porcentagens variaram de 0,07 a $0,19 \%$ (Tab. 3). Tais concentrações são consideradas significativas quando comparadas com as regiões da Baía de Santos $(0,06 \%$; Teodoro 2006) e Baía de Guanabara $(0,13 \%$; Carreira 1994), as quais são consideradas ambientes com elevado grau de poluição.

Análise da origem da matéria orgânica e grau de oxiredução dos sedimentos Os resultados obtidos pelas razões $\mathrm{C} / \mathrm{N}$ variaram de 2,40 a 337 (Tab. 3). $\mathrm{O}$ valor anômalo encontrado no ponto 9 pode ser decorrente a menor preservação de $\mathrm{N}$ em relação ao $\mathrm{C}$ org (Bader 1955). O ponto 9 está posicionado a maior profundidade $(17 \mathrm{~m})$ tornando-o sub-ambiente de maior deposição em relação aos demais pontos.

De acordo com o proposto por Saito et al. (1989), a matéria orgânica encontrada na área de estudo possui origem marinha (zooplâncton e fitoplâncton) nos pontos 1 e 7 (razões abaixo de 10), origem continental, em decorrência a aumento de detritos de vegetais com elevado conteúdo de lignina e celulose, nos pontos 3 , 8,9 e 10 (razões acima de 20). Os pontos 2,5 e 6 , por sua vez, recebem contribuição mista de matéria orgâ- nica, ou seja, marinha e continental (razões entre 10 e 20). A variação dos valores obtidos para as razões $\mathrm{C} / \mathrm{N}$ em uma mesma região, como a observada neste estudo, pode estar relacionada a diferenças granulométricas entre um ponto e outro, a degradação seletiva dos componentes de matéria orgânica, bem como a menor taxa de preservação do N em relação ao C org (Bader 1955).

De acordo com os valores obtidos pelas razões C/P observou-se que a matéria orgânica em grande maioria é de origem bacteriana, o que pode estar relacionada à decomposição da matéria orgânica existente na região. Ainda de acordo com Lima (2000) a razão C/P pode ser indicativa do potencial de oxi-redução dos sedimentos. Segundo a autora baixos valores de razão C/P podem inferir ambiente redutor em decorrência de elevada concentração de $\mathrm{P}_{2} \mathrm{O}_{5}$, proveniente da matéria orgânica.

No tocante as razões $\mathrm{C} / \mathrm{S}$, os valores encontrados variaram de 0,8 a 19,9. Valores inferiores a 3, indicando ambiente redutor, foram observados nos pontos 1, 3, 5, 6 e 7. Sub-ambientes oxidantes, por sua vez, foram observados nos pontos 2,8 e 9 . No ponto 10 , o valor encontrado, 3,24, o caracteriza como posicionado em ambiente com tendências redutoras. Os valores das razões $\mathrm{C} / \mathrm{S}$ obtidos, corroboram com o potencial de oxi-redução observado pelas razões $\mathrm{C} / \mathrm{P}$, ou seja, com exceção do ponto 2 , em todos os pontos com matéria orgânica de origem bacteriana, os sedimentos são redutores. Aparentemente a baixa dinâmica das correntes de fundo na área de estudo (Barcellos \& Furtado 1999), associada ao aporte de matéria orgânica disposto pelo emissário submarino está transformando a região onde estão posicionados os difusores em ambiente anóxico. 
CONCLUSÕES Os resultados de qualidade das águas na área de influência do despejo emissário do Araçá não apresentaram alterações significativas em relação à concentração de nutrientes ou contaminação microbiológica no momento da amostragem. Estes resultados podem estar associados à diluição da pluma de esgotos pelas correntes marrinhas presentes no canal ou pela sua ausência quando o sistema de bombeamento do emissário é desativado para realização da manutenção do sistema, tornando estes resultados, muitas vezes pouco representativos.

A maioria dos dados geoquímicos indicou que a pluma de esgoto provavelmente, se dissipa preferencialmente na direção sul-sudeste, dispersada pelas correntes da região mais profunda do Canal de São Sebastião. As concentrações mais elevadas de C orgânico, $\mathrm{N}$ e P (total, orgânico e inorgânico) encontradas nos sedimentos dos pontos desta mesma região, confirmam esta suposição, indicando a área onde ocorre deposição destas espécies. Os valores elevados de nutrientes indicaram que os sedimentos da região circunjacente ao emissário estão em processo de enriquecimento. Também, constatou-se o acúmulo de matéria orgânica em decomposição com formação de zonas anóxicas.

Ao se comparar os resultados das variáveis de qualidade obtidos para a água com os sedimentológicos, constatou-se a importância destes últimos, uma vez que os sedimentos representam o depósito final do material particulado e dos poluentes a eles associados, registrando, em caráter mais permanente, a contaminação à qual o ecossistema aquático está sendo submetido.

Agracedimentos A FAPESP, pelo apoio financeiro (Proc. 02/02612-2) e concessão da bolsa iniciação científica para o primeiro autor. A CETESB, pela doação do material sedimentológico e permissão para utilização dos dados hidrográficos e microbiológicos. Ao Prof. Thomas Fairchild, pela correção do abstract.

\section{Referências}

Bader R.G. 1955. Carbon and nitrogen relations in surface and subsurface marine sediments. Geochimica Cosmochimica Acta, 7 (5/7):205-211.

Bandy O.L., Ingle Jr. J.C., Resig J.M. 1964. Foraminiferal trends, Laguna Beach outfall area, California. Limnology and Oceanography, 9(1):112-123.

Barcellos R.L. \& Furtado V.V. 1999. Processo sedimentar atual e a distribuição de carbono e nitrogênio orgânicos no Canal de São Sebastião (SP) e plataforma continental adjacente. Revista Brasileira de Oceanografia, 47:207221.

Barcellos R.L. \& Furtado V.V. 2001. Caracterização dos componentes da fração arenosa $(0,500 \mathrm{~mm} / 0,250 \mathrm{~mm})$ no Canal de São Sebastião. Pesquisas em Geociências, 28:35-51

Borrego J., Lopez M., Pendon J.G., Morales J.A. 1998. C/S ratios in estuarine sediments of the Odiel River-mouth, S. W. Spain. Journal of Coastal Research, 14(4):12761283 .

Brasil Lima G.M.S. De S. 1998. Efeitos do efluente doméstico do emissário submarino de São Sebastião (SP), sobre o fitoplâncton marinho: estudos de campo e de laboratório. Tese de Doutoramento, Instituto Oceanográfico, Universidade de São Paulo, 160p.

Carreira R. 1994. Carbono orgânico e especiação de fósforo em sedimentos da área de influência do emissário submarino de esgotos de Ipanema (ESEI). Dissertação de Mestrado, Pontifícia Universidade Católica do Rio de Janeiro, RJ, 100p.

Castro-Filho B.M. 1990. Wind driven currents in the channel of São Sebastião: winter, 1979. Boletim do Instituto Oceanográfico de São Paulo, 38:111-132.

COMPANHIA DE TECNOLOGIA DE SANEAMENTO AMBIENTAL (CETESB). 2005. Qualidade das águas litorâneas no estado de São Paulo: Balneabilidade das praias, 2004. São Paulo: CETESB, 331p.

CONSELHO NACIONAL DO MEIO AMBIENTE (CONA-
MA). 2005. Resolução $n^{\circ}$ 357. Disponível em: www.cetesb.sp.gov.br/Agua/praias/res_conama_357_05.pdf.

Conti L.A. 1998. Aplicação de técnicas de geoprocessamento na caracterização de aspectos morfossedimentares do Canal de São Sebastião, litoral norte do estado de São Paulo. Dissertação de Mestrado, Instituto Oceanográfico, Universidade de São Paulo, 84p.

da Costa R.L. \& Carreira R.S. 2005. A comparison between faecal sterols and coliform counts in the investigation of sewage contamination in sediments. Brazilian Journal of Oceanography, 53(3/4):157:167.

Eichler B.B, Duleba W., Souza S.H.M. 1995. Foraminíferos recentes do canal de São Sebastião, SP, e suas relações com os padrões de sedimentação. Revista Pesquisas, Rio Grande do Sul, 22:12-20.

Folk R.L. \& Ward W.C. 1957. Brazos river bar: a study in the significance of grain size parameters. Journal of Sedimentary Petrology, 27:3-27.

Fontes R.F.C. 1995. As correntes no canal de São Sebastião. Dissertação de Mestrado, Instituto Oceanográfico, Universidade de São Paulo, 159p.

FUNDAÇÃO DE ESTUDOS E PESQUISAS (FUNDESPA). 1999. Levantamento oceanográfico da área diretamente afetada por efluentes dos emissários submarinos de esgotos da SABESP, entre os municipios de São Sebastião e Mongaguá, Estado de São Paulo. Relatório final. Fundação de Estudos e Pesquisas Aquáticas, 2 volumes, 364p.

Furtado V.V. 1978. Contribuição ao estuda da sedimentação atual do Canal de São Sebastião, Estado de São Paulo. Tese de Doutoramento, Instituto de Geociências da Universidade de São Paulo, v. 1 (texto), 110p, v. 2 (figuras e tabelas), $105 \mathrm{p}$.

Furtado V.V. 1995. Sedimentação quaternária no Canal de São Sebastião. Publicação Especial Instituto Oceanográfico da USP, São Paulo, 11:27-35.

Griggs G.B. \& Johnson S. 1978. Bottom sediment contami- 
nation in the Bay of Naples, Italy. Marine Pollution Bulletin, 9:208-214.

Gross M.G. 1971. Carbon determination. In: Carver R.E. (ed.) Procedures in sedimentary petrology. New York: Wiley, p. 573-596.

Lamparelli C.C. 2006. Desafios para o licenciamento e monitoramento ambiental de emissários: a experiência de São Paulo: In: Lamparelli C.C. \& Ortiz J.P. (eds.) Emissários Submarinos: Projeto, avaliação de impacto ambiental e monitoramento. São Paulo, Secretaria do Meio Ambiente, 240p. Disponível em: http://www.cetesb.sp.gov.br/ Agua/praias/publicacoes.asp.

Larssoneur C., Bouysse P., Aufret J.P. 1982. The superficial sediments of the English Channel and its Western Approach. Sedimentology, 19(6):851-864.

Legg J.O. \& Black C.A. Determination of organic phosphorus in soils: II. Ignition method. Soil Science Society of America Proceedings, 19:139-143.

Lima M.R.B.L.M.A. 2000. Natureza e origem da matéria orgânica depositada nos sedimentos superficiais ao longo da plataforma continental entre as cidades do rio de Janeiro (RJ) e São Francisco do Sul (SC). Dissertação de Mestrado, Universidade de São Paulo, Instituto Oceanográfico, $115 \mathrm{p}$.

Miranda L.B. 1982. Análise de Massas de água da plataforma continental e da região oceânica adjacente: Cabo de São Tomé (RJ) e Ilha de São Sebastião (SP). Tese de Livre Docência, Universidade de São Paulo, Instituto Oceanográfico, São Paulo, 125p.

Miranda L.B. \& Castro-Filho B.M. 1995. Variabilidade da circulação e do transporte de volume no Canal de São Sebastião (SP): outono de 1980. Publicação especial do Instituto Oceanográfico, São Paulo, 11:1-9.

Rebello A.L., Ponciano C.R., Melges L.H. 1988. Avaliação da produtividade primária e da disponibilidade de nutrientes na Baía de Guanabara. Anais da Academia Brasileira de Ciências, 60:419-430.

Ruttenberg K.C. \& Goñi M.A. 1997. Phosphorus distribution, C:N:P: ratios, and $\delta^{13} \mathrm{C}_{\mathrm{oc}}$ in artic, temperate, and tropical coastal sediments: tools for characterizing bulk sedimentary organic matter. Marine Geology, 139:123145.

Suguio K. 1973. Introdução à Sedimentologia. São Paulo, Edgard Blücher/EDUSP, 317p.

Saito Y., Nishimura A., Matsumoto F. 1989. Transgressive sand sheet covering the shelf and upper slope off Sendai, Northeast Japan. Marine Geology, 89(3/4):245-258.

Teodoro A.C. 2006. Estudo hidrogeoquímico, sedimentológico e de foraminíferos em áreas da Baixada Santista, SP, submetidas a disposição oceânica de esgotos. Dissertação de Mestrado, Instituto de Geociências, Universidade de São Paulo, 166p.

UNESCO. 1973. International Oceanographic Tables. Wormley, 2, 141p.

Zagatto E.A.G., Jacintho A.O., Reis B.F., Krug F.J., Bergamin Filho H., Pessenda L.C.R., Mortatti J., Giné M.F. 1981. Manual de análises de plantas e águas empregando sistemas de injeção em fluxo. Piracicaba: Universidade de São Paulo, CENA/Seção de Química Analítica, 45p.

Wentworth C.K. 1922. A scale of grade and class terms for clastics sediments. The Journal of Geology, 30(1):377392.

Manuscrito ID 10803

Submetido em 28 de fevereiro de 2008

Aceito em 20 de setembro de 2008 Sistema eletrônico de submissão 